\title{
Influence of Long-Tailed Alcohols on the Solubilisation of Cationic DHAB Bilayers
}

\author{
Johan A. Linthorst, Jaap E. Klijn and Jan B.F.N. Engberts* \\ Physical Organic Chemistry Unit, Stratingh Institute University of Groningen, Nijenborgh 4, 9747 AG \\ Groningen, The Netherlands. \\ * Author to whom correspondence should be addressed; e-mail: j.b.f.n.engberts@chem.rug.nl \\ Tel.: (+31)-50-3634242; Fax (+31)-50-3634296
}

Dedicated to Prof. Marvin Charton

Received: 27 February 2004 / Accepted: 19 March 2004 / Published: 31 January 2005

\begin{abstract}
The effects of $n$-decanol and cetyl alcohol incorporated into cationic di- $n$-hexadecyldimethylammonium bromide (DHAB) bilayers on the packing and the resistance against solubilisation by Triton X-100 have been investigated. Solubilisation experiments revealed that the mismatch between the $\mathrm{C}_{10}$-tail of $n$-decanol with the DHAB-tails does not affect the structural integrity of the vesicles. On the contrary, upon increasing amounts of cetyl alcohol, of which the tail matches in size with the DHAB-tails, breakdown of the vesicles is promoted, whereas complete solubilisation is strongly hampered. The system is further investigated by DSC and cryo-EM experiments. In addition, the effects of n-decanol and cetyl alcohol embedded into DHAB bilayers on the vesicular rate constants for the decarboxylation of 6-nitrobenzisoxazole-3-carboxylate (6-NBIC) suggest that both alcohols affect the structure of the Stern region in an equal manner, leading to a decrease in the catalysis. Therefore, it is concluded that addition of the alcohols leads to changes in properties of the interior of the bilayer, rather than the polar-apolar interface.
\end{abstract}

Keywords: $n$-Decanol; cetyl alcohol; TritonX-100; bilayers; vesicles; bilayer fragments; decarboxylation; 6-NBIC; solubilisation; DSC; cryo-EM

\section{Introduction}

Complex mixtures of steroids, lipids and proteins are the main components in biological membranes [1-3]. Both leaflets in biomembranes have different compositions, which makes these biomembranes very complex. In addition to these complexities, the distribution of the lipids over the 
leaflets is a nonrandom one [4-10]. The composition of these membranes plays a key role in several biological processes, which are influenced by the interactions between (different) components of the membranes [11].

Synthetic bilayer vesicles are interesting model systems because of their structural relationship with biological membranes. These vesicles have therefore been used as cell membrane mimics. For instance, Eliasz et al. [12] investigated the interactions between various alcohols, carboxylic acids and single-tailed quaternary ammonium salts with 1,2-dipalmitoyl-sn-glycero-3-phosphocholine (DPPC). They showed, using differential scanning calorimetry (DSC), that the main phase transition temperature $\left(T_{\mathrm{m}}\right)$ is strongly influenced by the membrane composition. Linear alcohols and linear carboxylic acids with short tails in comparison with the phospholipid tails lower the $T_{\mathrm{m}}$ drastically.

In comparable studies the effects of various $n$-alkanols on different phospholipids have been examined [13-17]. It has been found that short-tailed alcohols lower the $T_{\mathrm{m}}$ (by ca. $20^{\circ} \mathrm{C}$ ) and are inducing a broadening of the $T_{\mathrm{m}}$ transitions. In addition to these phenomena, it has also been found that the binding of these alcohols can result in a disappearance of pre-transitions. This phenomenon has also been observed for the long-tailed alcohol dodecanol, but in contrast to the short-tailed alcohols, addition of dodecanol can lead to an increase in $T_{\mathrm{m}}$ by ca. $15^{\circ} \mathrm{C}$. Depending on the phospholipids used, $n$-decanol lowers or increases $T_{\mathrm{m}}$. Generally, the nature of the alkyl chain of the alcohols also plays a role in the incorporation of alcohols. For instance, vesicles are more strongly affected by branched alcohols in comparison with linear alcohols [18]. The effects described so far are mole-fraction dependent.

In the present study our interest is focused on the incorporation of increasing amounts of $n$-decanol and cetyl alcohol into cationic DHAB bilayers. Due to their large hydrophobic part and poor solubility in water, the alcohols bind strongly to membranes [12,19]. These alcohols were chosen on the basis of the match, in the case of cetyl alcohol, and mismatch, for $n$-decanol, with the length of the $\mathrm{C}_{16}$-tails of DHAB. A major goal of this study is to determine the effects of these matching- and mismatching tails.

Most studies on mixed (DHAB) aggregates mainly focus on the determination of the main phase transition temperature $\left(T_{\mathrm{m}}\right)[20,21]$, as well as on the phase diagrams [14,22] and other related characteristics of the aggregates. Here we report the kinetic effects of two types of $\mathrm{DHAB} / \mathrm{C}_{n} \mathrm{OH}(n=$ $10,16)$ mixtures on the unimolecular decarboxylation of 6-nitrobenzisoxazole-3-carboxylate (6-NBIC) (Scheme 1). This kinetic probe has been widely used in biophysical studies and is sensitive to the local micropolarity [23-26], which makes it a proper model reaction for investigation of composition changes in membranes. In addition, the reaction is also highly sensitive to hydrogen-bonding interactions which stabilize 6-NBIC by forming hydrogen-bonds with the carboxylate group [23-26]. By contrast, an increase in medium polarity will increase the first-order rate constant. 
Scheme 1. Decarboxylation of 6-nitrobenzisoxazole-3-carboxylate anion (6-NBIC).

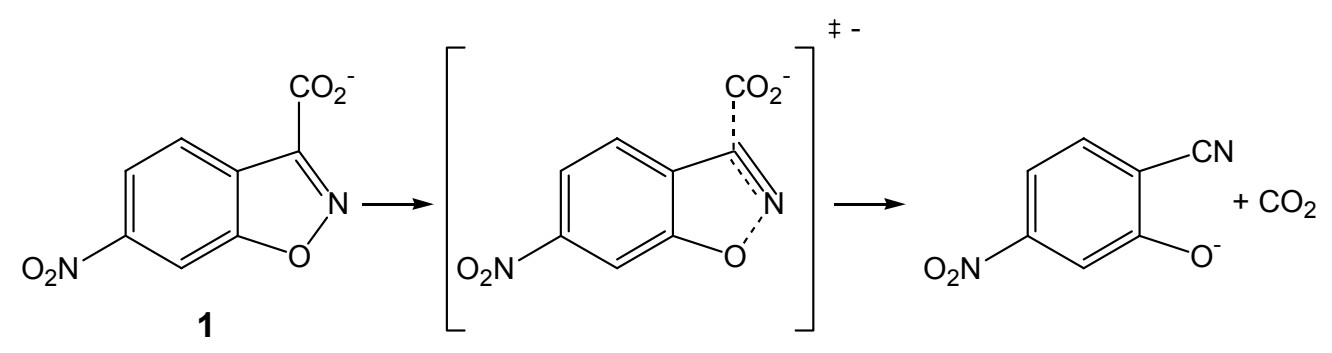

The pseudophase model $[27,28]$ is used for determination of the amphiphilic rate constants:

$$
k_{\mathrm{obs}}=\frac{k_{\mathrm{w}}^{\prime}+k_{\mathrm{amph}}^{\prime} K_{\mathrm{NBIC}}[\mathrm{Amph}]}{1+K_{\mathrm{NBIC}}[\mathrm{Amph}]}
$$

where [Amph] is the concentration of the amphiphile, $K_{\mathrm{NBIC}}$ is the binding constant of 6-NBIC to the vesicles and $k^{\prime}{ }_{\mathrm{w}}$ and $k^{\prime}$ amph represent the first-order rate constants in, respectively, the aqueous and amphiphilic pseudophases.

When 6-NBIC is fully bound to the vesicles, as in our case, (i.e., $K_{\mathrm{NBIC}}[\mathrm{Amph}] \gg 1$ and $k^{\prime}{ }_{\text {amph }} K_{\mathrm{NBIC}}[\mathrm{Amph}] \gg k^{\prime}{ }_{\mathrm{w}}$ ), equation [1] is reduced to the following equation:

$$
k_{\mathrm{obs}}=k_{\mathrm{amph}}^{\prime}
$$

Solubilisation of the bilayer vesicles by detergents (e.g. TritonX100, sodium dodecyl sulfate (SDS)) can give valuable information about the packing of the membrane and its resistance against detergents. A typical solubilisation profile is shown in Figure 1. This profile can be divided into three stages $[29,30]$. In the first stage the detergent is adsorbed by the vesicles, resulting in swelling. At a certain detergent concentration $\left(R_{\text {sat }}\right)$ the bilayers are saturated with detergent and from this point the vesicles are starting to solubilise upon addition of more detergent. This is the start of the intermediate region which consists of mixed micelles and vesicles. When all the vesicles are solubilised $\left(R_{\text {sol }}\right)$ by the detergent only mixed micelles are present and the turbidity levels off. Adding more detergent induces no more changes in the turbidity.

Although turbidity is a non-discriminating technique, its sensitivity is good enough to determine the saturation and solubilisation point accurately as a consequence of the large increase of the scattered intensity of light with particle size [31]. Therefore, almost any "large" particle (e.g. small vesicles, bilayer fragments) will be detected, hence the reported $R_{\text {sol }}$ values indicate the point of complete solubilisation. Additional evidence of partial vesicle solubilisation between $R_{\text {sat }}$ and $R_{\text {sol }}$ comes from cryo-electron microscopy experiments involving detergent-induced vesicle solubilisation of vesicles formed from phospholipids [32,33]. Above $R_{\text {sat }}$, besides spherical micelles, vesicles that have holes are observed, whereas above $R_{\text {sol }}$ no longer vesicles or bilayer fragments are found. It should be noted that in the present paper we are interested in trends, rather than absolute values. 
Besides the kinetic and solubilisation measurements, we have also used other techniques for characterisation of the $\mathrm{DHAB} / \mathrm{C}_{10} \mathrm{OH}$ mixtures: DSC measurements to determine the main phase transition temperature of different $\mathrm{DHAB} / \mathrm{C}_{10} \mathrm{OH}$ mixtures and cryo-electron microscopy for a morphological identification of the different $\mathrm{DHAB} / \mathrm{C}_{10} \mathrm{OH}$ mixtures.

Figure 1. Example of a solubilisation profile.

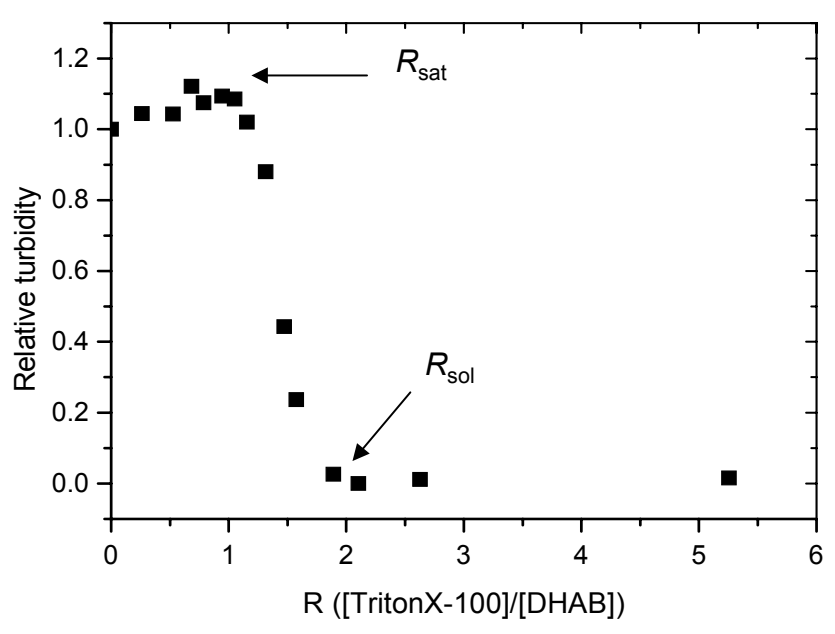

\section{Results and Discussion}

\section{Kinetics}

Figure 2 shows $k_{\text {obs }}$ values for the decarboxylation of 1 versus the amount of $n$-decanol and cetyl alcohol present in the DHAB bilayers. The rate profiles for both alcohols show that the rate is slowed down with increasing amounts of $n$-decanol or cetyl alcohol in the $\mathrm{DHAB} / \mathrm{C}_{n} \mathrm{OH}(n=10,16)$ mixtures. This pattern probably originates from a change in the hydrogen-bonding interactions between water molecules in the vicinity of the vesicular surface and the hydroxyl group of the alcohols with the carboxylate unit of the reactant and the activated complex. As already noted, hydrogen bonds lower the Gibbs energy of the initial state of 6-NBIC relatively to the activated complex. The net result of this behaviour is that the Gibbs energy of activation will rise upon an increase in $n$-decanol or cetyl alcohol in the $\mathrm{DHAB} / \mathrm{C}_{n} \mathrm{OH}(n=10,16)$ mixtures. The data in Figure 2 show that the differences between $\mathrm{DHAB} / \mathrm{C}_{10} \mathrm{OH}$ and $\mathrm{DHAB} / \mathrm{C}_{16} \mathrm{OH}$ mixtures are negligible. This observation makes it unjustified to attribute the differences to a difference in the type of alcohols present. For clarity, the $k_{\text {obs }}$ found for $0 \mathrm{~mol}^{2} \mathrm{C}_{n} \mathrm{OH}$ and $50 \mathrm{~mol} \% \mathrm{C}_{n} \mathrm{OH}(n=10,16)$, differ by a factor of about 3.5 , which is quite small.

The rate constants observed are comparable with those found for hydrophobically and electrostatically modified polyacrylamides as cosolutes. These compounds induce rate constants of an order of magnitude of $10^{-3} \mathrm{~s}^{-1}$ [34-36]. In addition, the $k_{\mathrm{obs}}$ found for cationic micelles formed from $n$ hexadecyltrimethylammonium bromide $(\mathrm{CTAB})$ at $30^{\circ} \mathrm{C}$ is in the order of magnitude of $10^{-4} \mathrm{~s}^{-1}$ $[25,37]$, which is comparable with the $k_{\mathrm{obs}}$ found for DHAB at $35^{\circ} \mathrm{C}$. Comparable $k_{\text {obs }}$ values at a temperature of $30^{\circ} \mathrm{C}$ are also found for vesicles containing different amounts of di- $n$ octadecyldimethylammonium chloride (DODAC) [28]. The comparisons observed, suggest that 
DHAB bilayers do not differ significantly in micropolarity and hydrogen-bonding propensity from $\mathrm{CTAB}$ and DODAC aggregates.

Figure 2. First-order rate constants for the decarboxylation of $\mathbf{1}$ embedded in $\mathrm{DHAB}$ vesicles containing $\mathrm{C}_{10} \mathrm{OH}(\bullet)$ and $\mathrm{C}_{16} \mathrm{OH}(\circ)$. Error bars denote the standard deviation of at least 5 independent measurements.

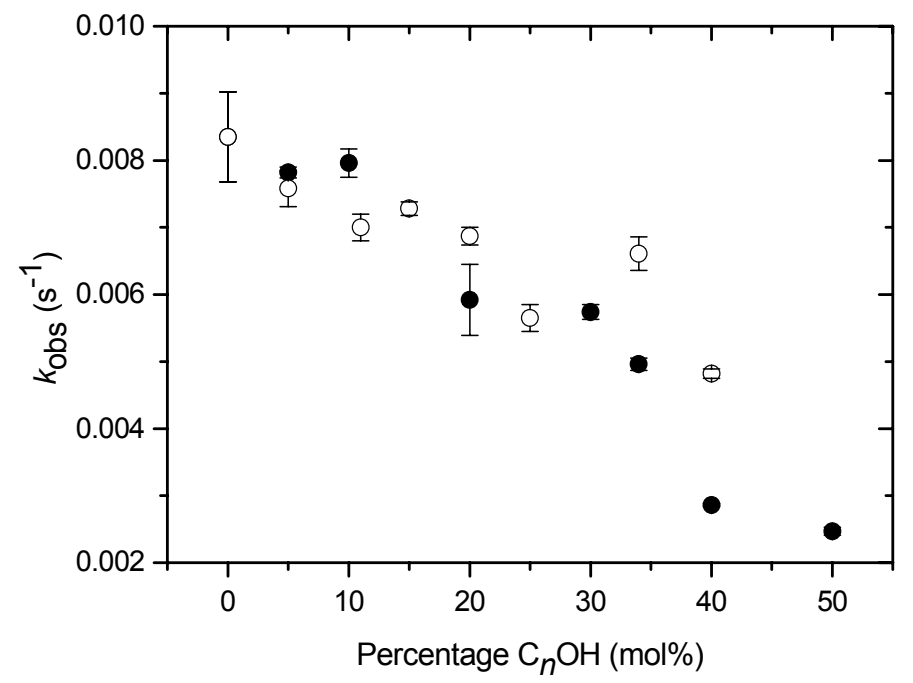

Solubilisation of $\mathrm{DHAB} / \mathrm{C}_{n} \mathrm{OH}(n=10,16)$ mixtures

Figures 3 and 4 outline the $R_{\mathrm{sat}}$ and $R_{\mathrm{sol}}$ relationships, between [TritonX-100] and [Amph] for different $\mathrm{DHAB} / \mathrm{C}_{n} \mathrm{OH}(n=10,16)$ mixtures. In these plots, $[\mathrm{TX}]_{\text {tot }}$ represents the overall concentration TritonX-100 and obeys the expressions 3 and 4 [25,38,39]:

$$
\begin{aligned}
& {[\mathrm{TX}]_{\mathrm{tot}}=[\mathrm{TX}]_{\mathrm{w}}+[\mathrm{TX}]_{\mathrm{amph}}} \\
& {[\mathrm{TX}]_{\mathrm{tot}}=[\mathrm{TX}]_{\mathrm{w}}+R_{\mathrm{b}}[\mathrm{amph}]}
\end{aligned}
$$

In these expressions, the aqueous and amphiphilic [TritonX-100] are given by $[\mathrm{TX}]_{\mathrm{w}}$ and $[\mathrm{TX}]_{\mathrm{amph}}$, respectively, where $R_{\mathrm{b}}$ is given by

$$
R_{\mathrm{b}}=\frac{[\mathrm{TX}]_{\mathrm{amph}}}{[\mathrm{amph}]}
$$

In equations [4] and [5] [amph] is the molar concentration of amphiphile and additive. As can be seen in equation [4], the slopes of the plots in Figure 3 and 4 represent the $R_{\mathrm{b}}$ values, which are the amounts of TritonX-100 bound to the amphiphilic pseudophases. The intercept with the y-axis represents the aqueous concentration of TritonX-100. From the ratio of the slope to the intercept the binding constant of detergent molecules to the vesicles $\left(K_{\text {det }}\right)$ can be calculated via equation [6]:

$$
K_{\mathrm{det}}=\frac{[\mathrm{TX}]_{\mathrm{amph}}}{[\mathrm{TX}]_{\mathrm{w}}[\mathrm{amph}]}
$$


However, due to scattering in the experimental data, extrapolation to zero amphiphile concentration and the relatively small value of the intercept compared to the slope, the error in $K_{\text {det }}$ will be large. Therefore, we refrained from calculating the binding constant.

The data in Figure 3 indicate that the composition of the bilayer $\left(R_{\mathrm{b}}\right)$ at the point of saturation (i.e. the slope of the plots in Figure 3) is independent of the mole fraction of incorporated $n$-decanol or cetyl alcohol. Except that the presence of over $15 \mathrm{~mol} \%$ of cetyl alcohol lowers $R_{\mathrm{b}}$ at the saturation point by a factor of around 2 . This means that less TritonX-100 is required to saturate the vesicles with detergent, if cetyl alcohol is present.

In Figure 4 it can be seen that for the solubilisation point $R_{\mathrm{b}}$ is constant upon increasing mole fraction of $n$-decanol, but increases linearly with increasing mole fraction of cetyl alcohol. At $35 \mathrm{~mol} \%$ of cetyl alcohol $R_{\mathrm{b}}$ is more than twice as large. All data is summarised in Figure 5. It is surprising to notice that increasing mole fraction of $n$-decanol does not influence detergent saturation and solubilisation of DHAB vesicles. On the contrary, upon addition of cetyl alcohol less TritonX-100 is needed to saturate the membrane, but that more TritonX-100 is required to completely solubilise all material into mixed micelles.

The values observed in Figure 5 are comparable with those of TritonX-100 bound to PC vesicles. ${ }^{37}$ These vesicles are quite sensitive for the nature of the surfactant used. For instance, the $R_{\mathrm{b}}$ values for the ionic surfactants sodium cholate [40], sodium alkylsulfates, as well as alkyltrimethylammonium bromides [39] in PC membranes vary between 0.3 and 4 . These values depend strongly on the tail length of the surfactant.

The $R_{\mathrm{b}}$ values at the solubilisation point (between 1 and 3.5) are comparable with those found for solubilisation of 1-palmitoyl-2-oleoyl-sn-glycero-3-phosphocholine (POPC) vesicles by SDS[41], as well as solubilisation of phosphatidylcholine (PC) vesicles by different sugar-based surfactants [38]. The observed values for $R_{\mathrm{b}}$ upon addition of $n$-decanol are about 1.5 , which is quite small. These values are comparable with the solubilisation of PC vesicles by dodecyl- $\alpha-D-m a l t o s i d e$, as well as by some other sugar surfactants [38].

If the data would be analysed in terms of solely the concentration of amphiphile and not the concentration of amphiphile and alcohol, the slopes in Figures 3 and 4 would increase progressively with increasing alcohol content, leading to larger values of $R_{\mathrm{b}}$. However, such an approach underestimates the contribution of the alcohols to the total hydrophobic volume to which TX-100 binds. In the absence of knowledge about the molar volume of the alcohols and DHAB (and hence the binding cannot be expressed as a function of the total hydrophobic volume), it is a more accurate approach to use the concentration of amphiphile and alcohol. 
Figure 3A. $R_{\text {sat }}$ relationships between [TritonX-100] vs. $\left[\mathrm{DHAB}+\mathrm{C}_{16} \mathrm{OH}\right]:(\bullet) 0$ $\mathrm{mol} \% \mathrm{C}_{16} \mathrm{OH}(\diamond) 15 \mathrm{~mol} \% \mathrm{C}_{16} \mathrm{OH}(\boldsymbol{\bullet}) 25 \mathrm{~mol} \% \mathrm{C}_{16} \mathrm{OH}(\boldsymbol{\Delta}) 34 \mathrm{~mol} \%$ $\mathrm{C}_{16} \mathrm{OH}$.

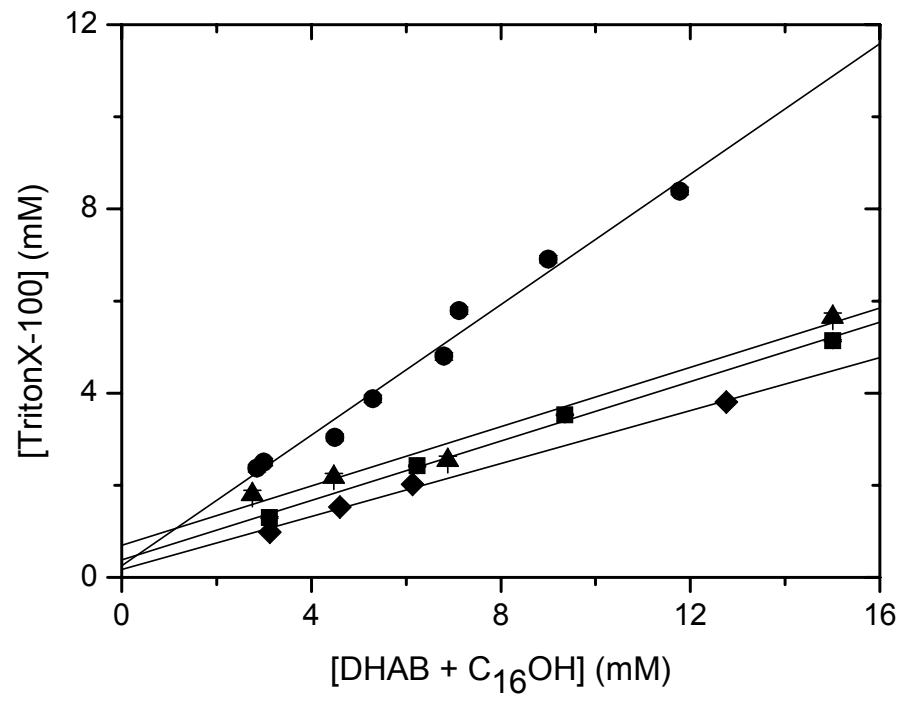

Figure 3B. $R_{\text {sat }}$ relationships between [TritonX-100] vs. [DHAB $\left.+\mathrm{C}_{10} \mathrm{OH}\right]:(\bullet) 0$ $\mathrm{mol} \% \mathrm{C}_{10} \mathrm{OH}(\diamond) 20 \mathrm{~mol} \% \mathrm{C}_{10} \mathrm{OH}(\bullet) 34 \mathrm{~mol} \% \mathrm{C}_{10} \mathrm{OH}(\boldsymbol{\Delta}) 50 \mathrm{~mol} \%$ $\mathrm{C}_{10} \mathrm{OH}$.

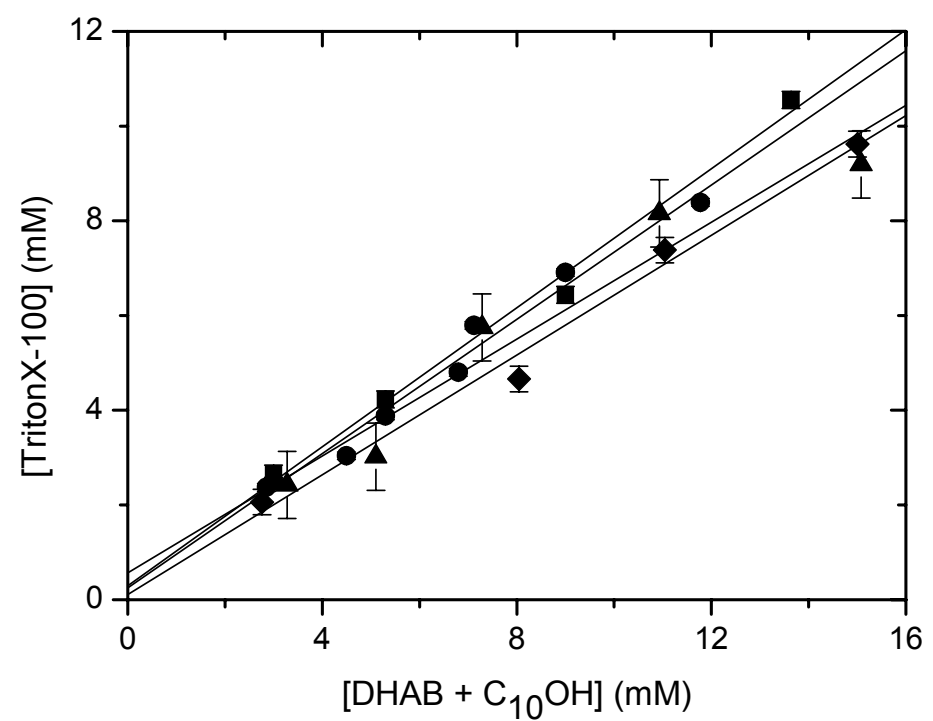


Figure 4A. $R_{\text {sol }}$ relationships between [TritonX-100] vs. [DHAB $\left.+\mathrm{C}_{16} \mathrm{OH}\right]$ : (०) 0 $\mathrm{mol} \% \mathrm{C}_{16} \mathrm{OH}(\diamond) 15 \mathrm{~mol} \% \mathrm{C}_{16} \mathrm{OH}(\square) 25 \mathrm{~mol} \% \mathrm{C}_{16} \mathrm{OH}(\Delta) 34 \mathrm{~mol} \%$ $\mathrm{C}_{16} \mathrm{OH}$.

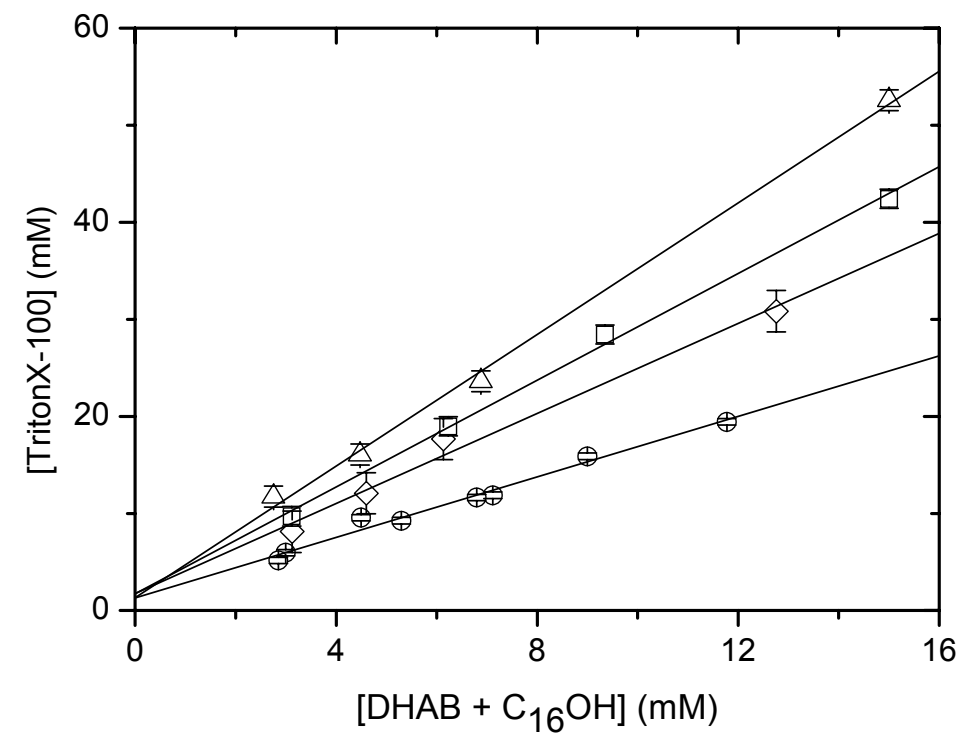

Figure 4B. $R_{\text {sol }}$ relationships between [TritonX-100] vs. [DHAB $\left.+\mathrm{C}_{10} \mathrm{OH}\right]$ : (O) 0 $\mathrm{mol} \% \mathrm{C}_{10} \mathrm{OH}(\diamond) 20 \mathrm{~mol} \% \mathrm{C}_{10} \mathrm{OH}(\square) 34 \mathrm{~mol} \% \mathrm{C}_{10} \mathrm{OH}(\Delta) 50 \mathrm{~mol} \%$ $\mathrm{C}_{10} \mathrm{OH}$.

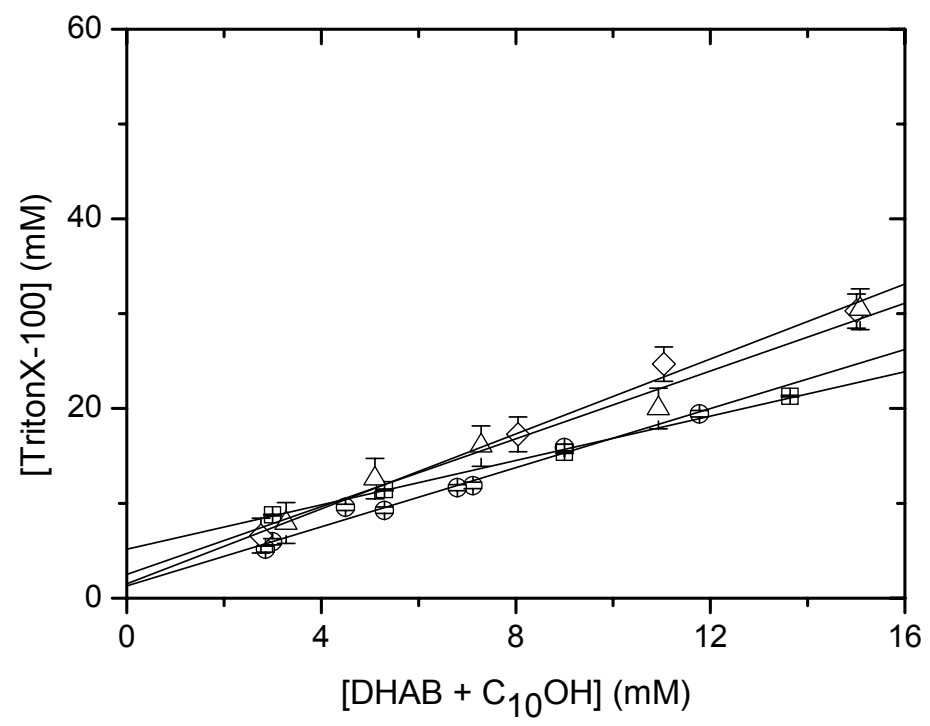


Figure 5. Slopes of Figure 3 and 4 vs. percentage of $\mathrm{C}_{n} \mathrm{OH}$ in the DHAB mixtures:

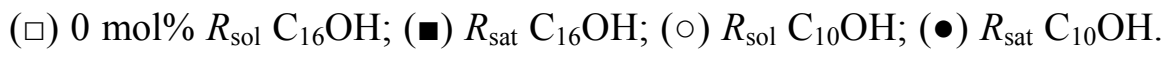
Lines are drawn to guide the eye

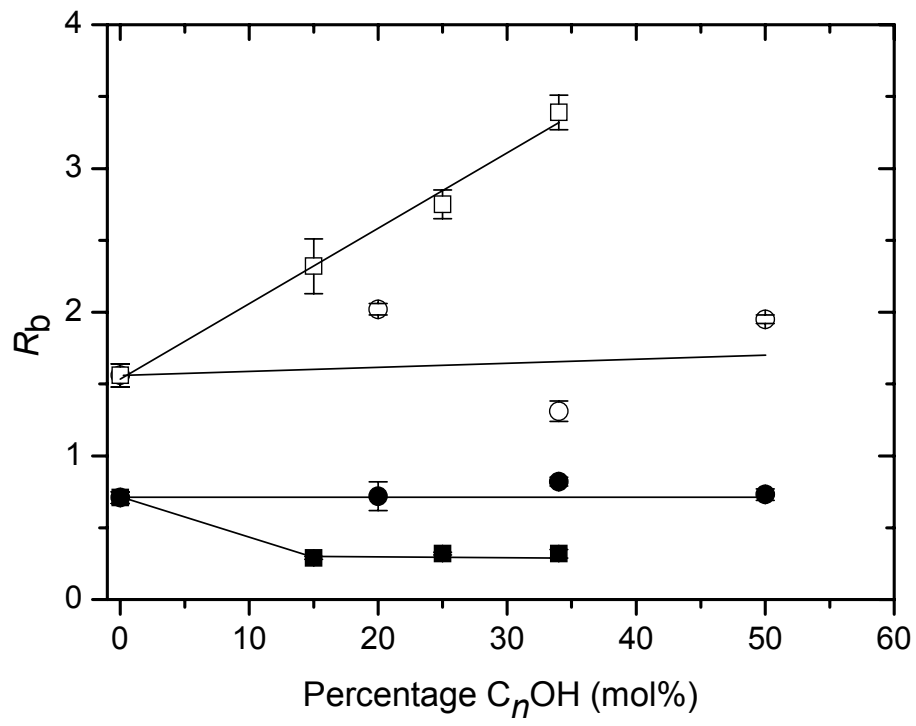

\section{Differential Scanning Calorimetry}

Figure 6 shows the dependence of the main phase transition temperature on the mole fraction of $\mathrm{C}_{10} \mathrm{OH}$ in $\mathrm{DHAB} / \mathrm{C}_{10} \mathrm{OH}$ vesicles. The $T_{\mathrm{m}}$ found for pure $\mathrm{DHAB}$ is $28^{\circ} \mathrm{C}$, which agrees with the literature $[19,20]$. Up to $20 \mathrm{~mol} \%$ of $\mathrm{C}_{10} \mathrm{OH} T_{\mathrm{m}}$ decreases until about $23^{\circ} \mathrm{C}$. Generally a lowering in $T_{\mathrm{m}}$ is explained by a decreased packing of the chains [21,42]. Upon further addition of $\mathrm{C}_{10} \mathrm{OH}$ the $T_{\mathrm{m}}$ increases again, reaching $30^{\circ} \mathrm{C}$ at $50 \mathrm{~mol} \%$ of $\mathrm{C}_{10} \mathrm{OH}$.

Figure 6. Relationship between $T_{\mathrm{m}}$ and the percentage of $\mathrm{C}_{10} \mathrm{OH}(\mathrm{mol} \%)$ in $\mathrm{DHAB} / \mathrm{C}_{10} \mathrm{OH}$ mixtures. The line is drawn to guide the eye.

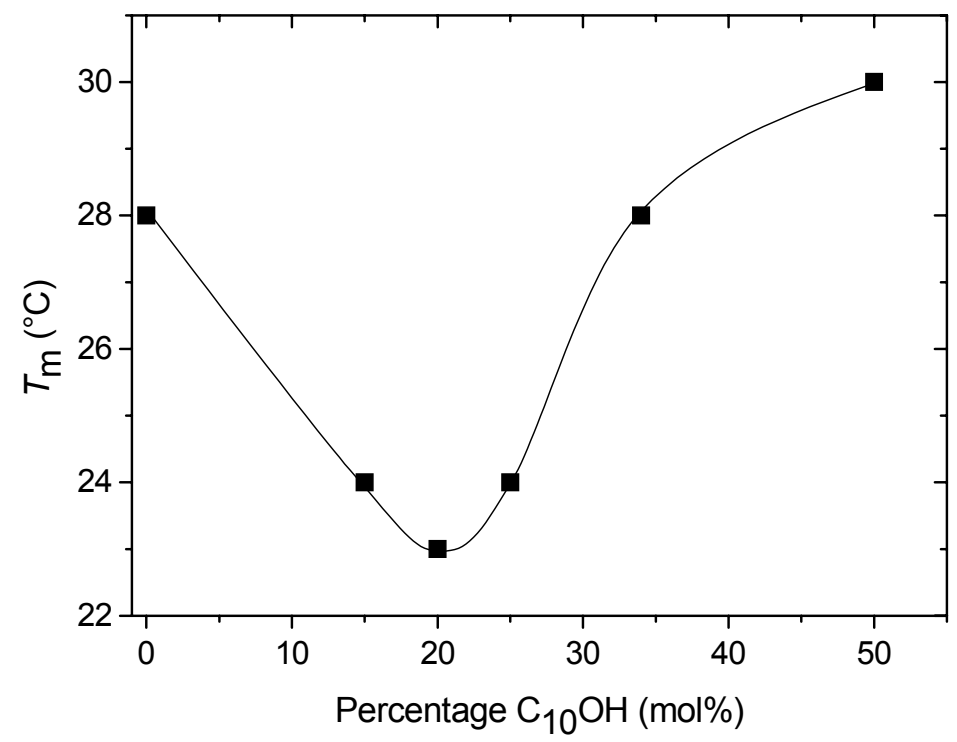


In the literature it has been reported that in mixtures of $n$-alcohols and phospholipids $n$-alcohols behave like amphiphiles leading to changes in the phase transition temperature that are linearly correlated with the melting point of the alcohols. A decrease in the phase transition temperature has been found upon the addition of alcohols with a short $\left(\leq \mathrm{C}_{8}\right)$ chain and an increase for alcohols with a long $\left(\geq \mathrm{C}_{12}\right.$ ) chain [12-17]. For mixtures of various $n$-alcohols and a synthetic quaternary ammonium amphiphile a decrease in the $T_{\mathrm{m}}$ at low mole fraction has been found, but an increase at higher mole fractions. The extent of the increase depends on the length of the alcohol [43].

The origin of the observed effects remains unclear. In general, the DSC scans show more than one peak, indicating several types of transitions, domain formation, or a combination of both. In the absence of more detailed information we refrain from an interpretation of these data.

\section{Cryo-electron microscopy}

The micrographs shown in Figure 7, suggest that the solutions contain closed vesicles, flat bilayers, and structures in between these extremes. In comparison with DHAB bilayers, the average size of the DHAB-30 mol\% $\mathrm{C}_{10} \mathrm{OH}$ aggregates is smaller. For synthetic amphiphiles open vesicle structures or bilayer fragments have been reported in the literature when the amphiphiles are below the main phase transition temperature, as is the case for the structures shown in Figure $7[44,45]$.

Figure 7. $\mathrm{DHAB}$ bilayers containing $0 \mathrm{~mol} \% \mathrm{C}_{10} \mathrm{OH}(\mathrm{A})$ and $30 \mathrm{~mol} \% \mathrm{C}_{10} \mathrm{OH}(\mathrm{B})$.

The size of the bar represents $100 \mathrm{~nm}$.
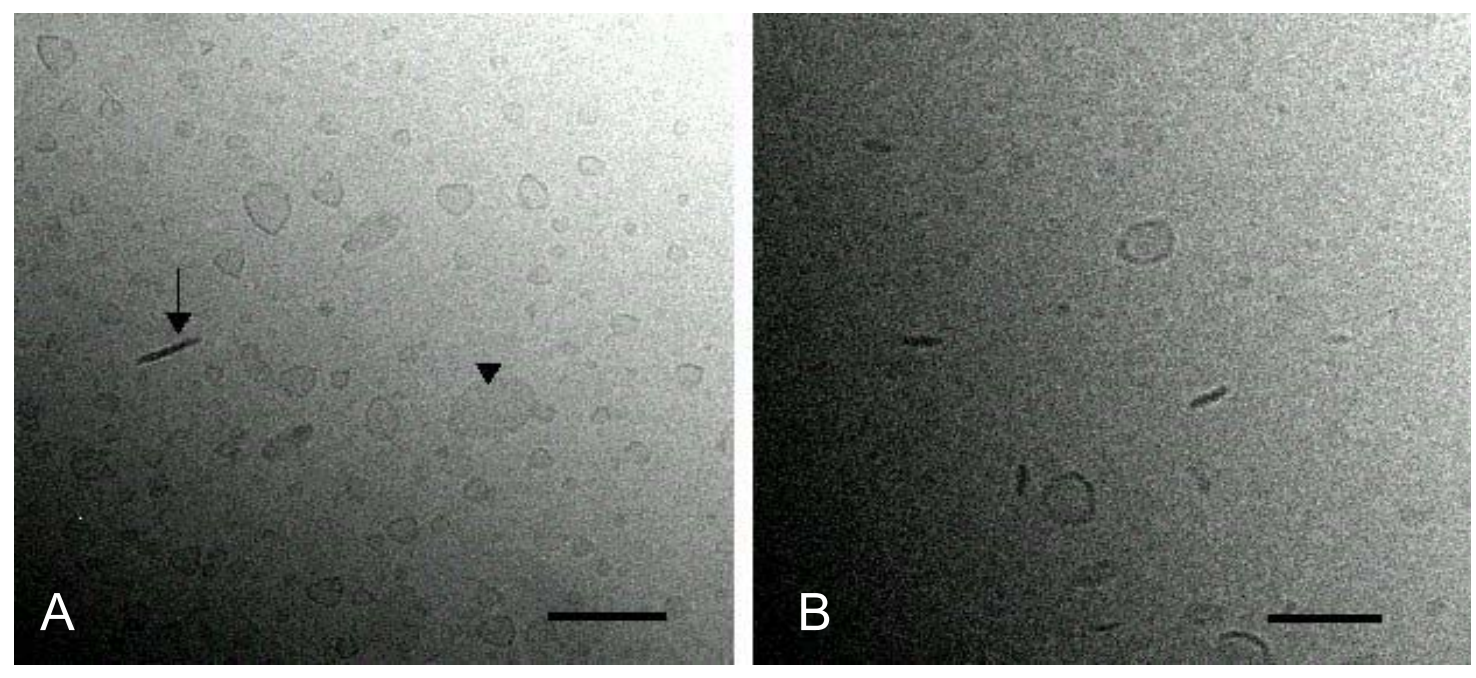

\section{Matching and mismatching tails}

The influence of match and mismatch of cetyl alcohol and $n$-decanol, respectively, with the $\mathrm{C}_{16^{-}}$ tails of DHAB is most apparent in the solubilisation experiments (Figure 5). Whereas, mismatch does not lead to changes in membrane composition ( $R_{\mathrm{b}}$ is constant) at the points of saturation and solubilisation, match leads to a strong increase in $R_{\mathrm{b}}$ for complete solubilisation of the vesicles upon increasing the amount of incorporated cetyl alcohol. In addition $R_{\mathrm{b}}$ decreases for the saturation point. On the contrary, the decrease in vesicular rate constant upon increasing alcohol content of the vesicles 
does not depend on the match or mismatch. It should be noted that the decarboxylation reaction takes place in the Stern region, whereas solubilisation of the bilayer depends on the membrane as a whole. Apparently, addition of both alcohols affects the Stern region is a similar manner, but the packing deeper in the bilayer is affected in a dissimilar manner. Considering that the hydroxyl group resides in the head group region of the amphiphile, it is reasonable that differences in packing are most pronounced at position remote from the polar-apolar interface. The decrease in catalysis is most likely a result of an increase in water concentration due to decrease in the (head group) packing.

The cryo-EM pictures show that $n$-decanol embedded into DHAB bilayers induces small morphological changes. Considering the DSC results, these changes are probably accompanied by changes in the packing of the $\mathrm{DHAB} / \mathrm{C}_{10} \mathrm{OH}$ bilayers $[42,45]$.

\section{Conclusions}

In this study we have outlined the different effects observed between matching and mismatching tails in vesicles formed from $\mathrm{DHAB}$ and $\mathrm{C}_{n} \mathrm{OH}(n=10$ or 16$)$. The results show that, besides small morphological changes and changes in the main phase transition temperature, upon increasing amounts $n$-decanol the composition of the membrane $\left(R_{\mathrm{b}}\right)$ at the points of saturation and solubilisation by TritonX-100 are not affected up to $50 \mathrm{~mol} \%$ of $n$-decanol. On the contrary, upon increasing amounts of cetyl alcohol the point of saturation is reached at a lower detergent to amphiphile ratio, but the point of solubilisation is reached at a higher detergent to amphiphile ratio.

The monotonic and alcohol-structure independent decrease in the vesicular rate constant of the unimolecular decarboxylation reaction of $\mathbf{1}$ upon increasing alcohol content suggests that changes in the bilayer mainly occur in the interior of the bilayer, rather than at the polar-apolar interface. In addition, the decrease in rate constant suggests a slight increase in the water content at the interface of the vesicles.

\section{Acknowledgements}

Dr. Marc Stuart is kindly acknowledged for his skilful cryo electron microscopy measurements on $\mathrm{DHAB} / \mathrm{C}_{10} \mathrm{OH}$ mixtures.

\section{Experimental}

\section{Materials}

DHAB ( $\geq 97 \%$ ), cetyl alcohol ( $\geq 99 \%)$ and TritonX-100 (98\%) were obtained from Fluka and were used without further purification. TritonX-100 was free of ethylene oxide and 1,4-dioxane. $n$-Decanol (99\%) was purchased from Aldrich. 6-Nitrobenzisoxazole-3-carboxylate (6-NBIC) was synthesised according to a literature procedure $[46,47]$ and was stored at $-20^{\circ} \mathrm{C}$. $\mathrm{DHAB} / \mathrm{C}_{n} \mathrm{OH}(n=10,16)$ mixtures were prepared by adding double distilled water to the amphiphiles. The mixtures were stored in a waterbath $\left(50^{\circ} \mathrm{C}\right)$ for at least $1 \mathrm{~h}$. After sonication for at least 10 minutes at $50^{\circ} \mathrm{C}$, the solution was extruded 11 times through a filter with a pore size of $400 \mathrm{~nm}$ at $45^{\circ} \mathrm{C}$. 


\section{Solubilisation measurements}

TritonX-100 was added from a freshly prepared aqueous stock solution to the solutions containing DHAB aggregates. The solubilisation processes were followed by monitoring the turbidity (absorption) at $410 \mathrm{~nm}$. Measurements were performed above the $T_{\mathrm{m}}$ at $35.0 \pm 0.1^{\circ} \mathrm{C}$ and were carried out using a Perkin Elmer $\lambda 5$ spectrophotometer. The $R_{\text {sol }}$ and $R_{\text {sat }}$ were determined graphically.

\section{Kinetic measurements}

The decarboxylation of 1 was monitored at $35.0 \pm 0.1^{\circ} \mathrm{C}$ by measuring the increase in the absorption at $410 \mathrm{~nm}$ for at least 5 half-lives after addition of $4 \mu \mathrm{l}$ of a $6 \mathrm{mM}$ stock solution of 1 in acetonitrile into a $0.9 \mathrm{ml}$ solution containing an alkaline surfactant solution. The stock solution of 1 was stored at $20^{\circ} \mathrm{C}$. The concentration of sodium hydroxide was 100 fold higher than the concentration of 6-NBIC. Measurements were performed using a Perkin Elmer $\lambda 5$ or a Perkin Elmer $\lambda 2$ spectrophotometer. The average error observed in the rate constants was $10 \%$.

\section{DSC measurements}

Differential Scanning Calorimetric (DSC) measurements were carried out with a VP-DSC microcalorimeter. A typical experiment was performed with a scan rate of $60^{\circ} \mathrm{C} / \mathrm{h}$ and an amphiphile concentration of $2 \mathrm{mM}$. Each scan was repeated at least 5 times.

\section{Cryo-Electron Microscopy}

The following procedure was used to perform cryo-electron microscopy: aliquots of amphiphile solutions were deposited on holey carbon grids; the excess solution was blotted off using filter paper. The samples were vitrified by rapid plunging into liquid ethane. The grids were transferred to a Gatan model 626 cryo holder and examined at ca. $-170{ }^{\circ} \mathrm{C}$ in a CM120 Philips microscope operating at 120 $\mathrm{kV}$. Micrographs were recorded under low dose conditions.

\section{References}

1. Gennis, R. B. In Biomembranes: Molecular Structure and Function; Springer-Verlag: New York, 1989; p. 20.

2. Darnell, J.; Lodish, H.; Baltimore, D. In Molecular Cell Biology; Scientific American Books: New York, 1990; p. 491.

3. Alberts, B.; Bray, D.; Lewis, J.; Raff, M.; Roberts, K.; Watson, J. D. In Molecular Biology of the Cell; Garland Publishing: New York, 1994; p. 477.

4. Ahmed, S. N.; Brown, D. A.; London, E. On the origin of sphingolipid/cholesterol-rich detergentinsoluble cell membranes: Physiological concentrations of cholesterol and sphingolipid induce formation of a detergent- insoluble, liquid-ordered lipid phase in model membranes Biochemistry 1997, 36, 10944.

5. Simons, K.; Ikonen, E. Functional rafts in cell membranes Nature 1997, 387, 569. 
6. London, E.; Brown, D. A. Insolubility of lipids in Triton X-100: physical origin and relationship to sphingolipid/cholesterol membrane domains (rafts) Biochim. Biophys. Acta 2000, 1508, 182.

7. Rietveld, A.; Simons, K. The differential miscibility of lipids as the basis for the formation of functional membrane rafts Biochim. Biophys. Acta 1998, 1376, 467.

8. Schroeder, R. J.; Ahmed, S. N.; Zhu, Y. Z.; London, E.; Brown, D. A. Cholesterol and sphingolipid enhance the Triton X-100 insolubility of glycosylphosphatidylinositol-anchored proteins by promoting the formation of detergent-insoluble ordered membrane domains $J$. Biol. Chem. 1998, 273, 1150.

9. Pralle, A.; Keller, P.; Florin, E. L.; Simons, K.; Horber, J. K. H. Sphingolipid-cholesterol rafts diffuse as small entities in the plasma membrane of mammalian cells J. Cell Biol. 2000, 148, 997.

10. Simons, K.; Ikonen, E. Cell biology - How cells handle cholesterol Science 2000, 290, 1721.

11. Zubay, G. Biochemistry; Addison-Wesley Publishing Company: Reading (USA), 1983.

12. Eliasz, A. W.; Chapman, D.; Ewing, D. F. Phospholipid Phase Transitions Biochim. Biophys. Acta 1976, 448, 220.

13. Hui, F. K.; Barton, P. G. Mesomorphic behavior of some phospholipids with aliphatic alcohols and other non-ionic substances Biochim. Biophys. Acta 1973, 296, 510.

14. Lee, A. G. Interactions between anesthetics and lipid mixtures. Normal Alcohols Biochemistry 1976, 15, 2448.

15. Mabrey, S.; Sturtevant, J. M. Incorporation of saturated fatty acid into phosphatidylcholine bilayers Biochim. Biophys. Acta 1977, 486, 444.

16. Jain, M. K.; Wu, N. M. Effects of Small Molecules on the Dipalmitoyl Lecithin Liposomal Bilayer J. Membrane Biol. 1977, 34, 157.

17. Zavoico, G. B.; Chandler, L.; Kutchai, H. Pertubation of egg phosphatidylcholine and dipalmitoylcholine multilamellar vesicles by $n$-alcohols. A fluorescent probe study Biochim. Biophys. Acta 1985, 812, 299.

18. Campos, A. M.; Abuin, E. B.; Lissi, E. A. Effect of a linear (1-octanol) and a branched (2,6dimethyl-4- heptanol) alkanol upon the properties of dipalmitoylphosphatidylcholine large unilamellar vesicles Colloids Surf. A 1995, 100, 155.

19. Aspée, A.; Lissi, E. A. Solubilization of alkanols in DPPC luvs - dependence on the alkanol concentration and topology J. Colloid Interface Sci. 1995, 175, 225.

20. Blandamer, M. J.; Briggs, B.; Cullis, P. M.; Irlam, K. D.; Kirby, S. D.; Engberts, J. B. F. N. Formation of vesicular bilayers in aqueous solutions containing mixtures of dialkyldimethylammonium bromides J. Mol. Liq. 1998, 75, 181.

21. Kacperska, A. DSC investigations of DDAB, DTAB and DHAB vesicle aqueous solutions in presence of SDS J. Therm. Anal. 2000, 61, 63.

22. Lee, A. G. Lipid phase-transitions and phase-diagrams .2. Mixtures involving lipids Biochim. Biophys. Acta 1977, 472, 285.

23. Kemp, D. S.; Paul, K. G. Decarboxylation of benzisoxazole-3-carboxylic acids. Catalysis by extraction of possible relevance to the problem of enzymatic mechanism. J. Am. Chem. Soc. 1970, 92, 2553.

24. Grate, J. W.; McGill, R. A.; Hilvert, D. Analysis of solvent effects on the decarboxylation of benzisoxazole-3-carboxylate ions using linear solvation energy relatinships: relevance to catalysis in an antibody binding site $J$. Am. Chem. Soc. 1993, 115, 8577. 
25. Talhout, R.; Engberts, J. B. F. N. Self-assembly in mixtures of sodium alkyl sulfates and alkyltrimethylammonium bromides: Aggregation behavior and catalytic properties Langmuir 1997, 13, 5001.

26. Brinchi, L.; Germani, R.; Goracci, L.; Savelli, G.; Bunton, C. A. Decarboxylation and dephosphorylation in new gemini surfactants. Changes in aggregate structures Langmuir 2002, $18,7821$.

27. Romsted, L. S. In Micellization, Solubilization and Microemulsions; Mittal, K. L., ed., Plenum Press: New York, 1977; p. 509.

28. Scarpa, M. V.; Araujo, P. S.; Schreier, S.; Sesso, A.; Oliveira, A. G.; Chaimovich, H.; Cuccovia, I. M. Effect of vesicles of dimethyldioctadecylammonium chloride and phospholipids on the rate of decarboxylation of 6-nitrobenzisoxazole-3-carboxylate Langmuir 2000, 16, 993.

29. Schurtenberger, P.; Mazer, N.; Kanzig, W. Micelle to Vesicle Transition in Aqueous-Solutions of Bile-Salt and Lecithin J. Phys. Chem. 1985, 89, 1042.

30. Kragh-Hansen, U.; le Maire, M.; Møller, J. V. The mechanism of detergent solubilization of liposomes and protein-containing membranes Biophys. J. 1998, 75, 2932.

31. Johnsson, M.; Wagenaar, A.; Stuart, M. C. A.; Engberts, J. B. F. N. Sugar-based gemini surfactants with $\mathrm{pH}$-dependent aggregation behavior: Vesicle-to-micelle transition, critical micelle concentration, and vesicle surface charge reversal Langmuir 2003, 19, 4609.

32. Edwards, K.; Almgren, M. Solubilization of lecithin vesicles by $\mathrm{C}_{12} \mathrm{E}_{8}-$ structural transitions and temperature effects J. Colloid Interface Sci. 1991, 147, 1.

33. Silvander, M.; Karlsson, G.; Edwards, K. Vesicle solubilization by alkyl sulfate surfactants: A cryo-TEM study of the vesicle to micelle transition J. Colloid Interface Sci. 1996, 179, 104.

34. Wang, G. J.; Engberts, J. B. F. N. Synthesis of hydrophobically and electrostatically modified polyacrylamides and their catalytic effects on the unimolecular decarboxylation of 6nitrobenzisoxazole-3-carboxylate anion Langmuir 1995, 11, 3856.

35. Wang, G. J.; Engberts, J. B. F. N. Synthesis and catalytic properties of non-cross-linked and cross-linked poly(alkylmethyldiallylammonium bromides) having decyl, octyl, and hexyl sidechains J. Org. Chem. 1995, 60, 4030.

36. Wang, G. J.; Engberts, J. B. F. N. Macromolecular flexibility and aggregation tendency of noncross-linked and crosslinked cationic polysoaps Eur. Polym. J. 1998, 34, 1319.

37. Brinchi, L.; di Profio, P.; Germani, R.; Savelli, G.; Spreti, N. Effect of ethanol on micellization and on decarboxylation of 6- nitrobenzisoxazole-3-carboxylate in aqueous cationic micelles $J$. Colloid Interface Sci. 2002, 247, 429.

38. Caussanel, F.; Andre-Barrès, C.; Lesieur, S.; Rico-Lattes, I. A comparative study of sugar-based surfactants for the solubilization of phosphatidylcholine vesicles Colloids Surf. B 2001, 22, 193.

39. Chu, S. C.; Hung, C. H.; Wang, S. C.; Tsao, H. K. Partition thermodynamics of ionic surfactants between phosphatidylcholine vesicle and water phases J. Chem. Phys. 2003, 119, 3441.

40. Memoli, A.; Annesini, M. C.; Petralito, S. Surfactant-induced leakage from liposomes: a comparison among different lecithin vesicles Int. J. Pharm 1999, 184, 227.

41. Tan, A. M.; Ziegler, A.; Steinbauer, B.; Seelig, J. Thermodynamics of sodium dodecyl sulfate partitioning into lipid membranes Biophys. J. 2002, 83, 1547. 
42. Carion-Taravella, B.; Lesieur, S.; Chopineau, J.; Lesieur, P.; Ollivon, M. Phase behavior of mixed aqueous dispersions of dipalmitoylphosphatidylcholine and dodecyl glycosides: A differential scanning calorimetry and X-ray diffraction investigation Langmuir 2002, 18, 325.

43. Klijn, J. E.; Engberts, J. B. F. N. The Kemp elimination in membrane mimetic reaction media. Probing catalytic properties of cationic vesicles formed from a double-tailed amphiphile and linear long-tailed alcohols or alkyl pyranosides Org. Biomol. Chem. 2004, 2, 1789.

44. Hammerström, L.; Velikian, I.; Karlsson, G.; Edwards, K. Cryo-tem evidence - sonication of dihexadecyl phosphate does not produce closed bilayers with smooth curvature Langmuir 1995, $11,408$.

45. Andersson, M.; Hammerström, L.; Edwards, K. Effect of bilayer phase-transitions on vesicle structure and its influence on the kinetics of viologen reduction J. Phys. Chem. 1995, 99, 14531.

46. Borsche, W. Über a-Dinitrophenyl-acetessigester und verwandte Verbindungen Chem. Ber. 1909, 42, 1310.

47. Lindemann, H.; Cissée, H. Ringöffnung bei Benz-a,b-isoxazolen Liebigs Ann. Chem. 1929, 469, 44.

Sample Availability: Available from the authors.

(C) 2005 by MDPI (http://www.mdpi.org). Reproduction is permitted for noncommercial purposes. 